\title{
Effectiveness of deformity-correction surgery for primary degenerative sagittal imbalance: a meta-analysis
}

\author{
Chang-Hyun Lee, MD, ${ }^{1}$ Chun Kee Chung, MD, PhD, ${ }^{2-5}$ Jee-Soo Jang, MD, PhD, ${ }^{6}$ \\ Sung-Min Kim, MD, PhD, ${ }^{7}$ Dong-Kyu Chin, MD, PhD, ${ }^{8}$ Jung-Kil Lee, MD, PhD, ${ }^{9}$ \\ Seung Hwan Yoon, MD, PhD, ${ }^{10}$ Jae Taek Hong, MD, PhD, ${ }^{11}$ Yoon Ha, MD, PhD, ${ }^{12}$ \\ Chi Heon Kim, MD, PhD, ${ }^{2-4}$ and Seung-Jae Hyun, MD, $\mathrm{PhD},{ }^{13}$ on behalf of the \\ Korean Spinal Deformity Research Society
}

\begin{abstract}
${ }^{1}$ Department of Neurosurgery, Ilsan Paik Hospital, Inje University College of Medicine, Goyang; '2Department of Neurosurgery, Seoul National University Hospital, Seoul National University College of Medicine; ${ }^{3}$ Neuroscience Research Institute, Seoul National University Medical Research Center; ${ }^{4}$ Clinical Research Institute, Seoul National University Hospital; ${ }^{5}$ Department of

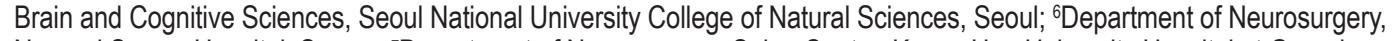
Nanoori Suwon Hospital, Suwon; ' Department of Neurosurgery, Spine Center, Kyung Hee University Hospital at Gangdong, Seoul; ${ }^{8}$ Department of Neurosurgery, Spine and Spinal Cord Institute, Gangnam Severance Spine Hospital, Yonsei University College of Medicine, Seoul; ' ${ }^{D}$ epartment of Neurosurgery, Chonnam University Hospital, Chonnam University College of Medicine, Gwangju; ${ }^{10}$ Department of Neurosurgery, Inha University Hospital, Inha University College of Medicine, Incheon; ${ }^{11}$ Department of Neurosurgery, St. Vincent's Hospital, College of Medicine, The Catholic University of Korea, Suwon; ${ }^{2}$ Department of Neurosurgery, Yonsei University College of Medicine, Severance Hospital, Seoul; and ${ }^{13}$ Department of Neurosurgery, Spine Center, Seoul National University Bundang Hospital, Seoul National University College of Medicine, Seoul, Republic of Korea
\end{abstract}

OBJECTIVE As life expectancy continues to increase, primary degenerative sagittal imbalance (PDSI) is diagnosed in an increasing number of elderly people. Although corrective surgery for this sagittal deformity is becoming more popular, the effectiveness of the procedure remains unclear. The authors aimed to collate the available evidence on the effectiveness and complications of deformity-correction surgery in patients with PDSI.

METHODS The authors carried out a meta-analysis of clinical studies regarding deformity correction in patients with PDSI. The studies were identified through searches of the PubMed, Embase, Web of Science, and Cochrane databases. Surgery outcomes were evaluated and overall treatment effectiveness was assessed in terms of the minimum clinically important difference (MCID) in Oswestry Disability Index (ODI) values and pain levels according to visual analog scale (VAS) scores and in terms of restoration of spinopelvic parameters to within a normal range. Data are expressed as mean differences with $95 \%$ Cls.

RESULTS Ten studies comprising 327 patients were included. The VAS and ODI values improved after deformity-correction surgery. The smallest treatment effect exceeded the MCID for VAS values (4.15 [95\% CI 3.48-4.82]) but not for $\mathrm{ODI}$ values (18.11 [95\% $\mathrm{Cl} 10.99-25.23])$. At the final follow-up visit, the mean lumbar lordosis angle $\left(-38.60^{\circ}[95 \% \mathrm{Cl}\right.$ $-44.19^{\circ}$ to $\left.\left.-33.01^{\circ}\right]\right)$, thoracic kyphosis angle $\left(31.10^{\circ}\left[95 \% \mathrm{Cl} 24.67^{\circ}-37.53^{\circ}\right]\right)$, C-7 sagittal vertical axis $(65.00 \mathrm{~mm}[95 \%$ $\mathrm{Cl} 35.27-94.72 \mathrm{~mm}])$, and pelvic tilt angle $\left(30.82^{\circ}\left[95 \% \mathrm{Cl} 24.41^{\circ}-37.23^{\circ}\right]\right)$ remained outside their normal ranges. Metaregression analyses revealed a significant effect of ODI change in relation to lumbar lordosis change $(p=0.004)$. After a mean of 2 years after deformity correction, the mean lumbar lordosis angle and C-7 sagittal vertical axis decreased by $5.82^{\circ}$ and $38.91 \mathrm{~mm}$, respectively, and the mean thoracic kyphosis angle increased by $4.7^{\circ}$. The incidences of proximal junctional kyphosis and pseudarthrosis were $23.7 \%$ and $12.8 \%$, respectively.

CONCLUSIONS Deformity correction substantially relieves back pain for about 2 years in adult patients with PDSI. Sufficient surgical restoration of lumbar lordosis can lead to substantial improvement in patient disability and reduced decompensation. Deformity correction represents a viable therapeutic option for patients with PDSI, but further technical advancements are necessary to achieve sufficient lumbar lordosis and reduce complication rates.

https://thejns.org/doi/abs/10.3171/2017.3.SPINE161134

KEY WORDS degenerative; sagittal; imbalance; deformity; meta-analysis; lumbar

ABBREVIATIONS LL = lumbar lordosis; MCID = minimum clinically important difference; ODI = Oswestry Disability Index; PDSI = primary degenerative sagittal imbalance; $\mathrm{PI}=$ pelvic incidence; $\mathrm{PJK}=$ proximal junctional kyphosis; $\mathrm{PT}=$ pelvic tilt; $\mathrm{SVA}=$ sagittal vertical axis; $\mathrm{TK}=$ thoracic kyphosis; $\mathrm{VAS}=$ visual analog scale.

SUBMITTED October 2, 2016. ACCEPTED March 3, 2017.

INCLUDE WHEN CITING Published online August 11, 2017; DOI: 10.3171/2017.3.SPINE161134. 
$\mathrm{L}$ UMBAR lordosis (LL) is unique to the human spine; intact sagittal spinal alignment of the spine enables humans to walk upright with minimal effort. ${ }^{38}$ Decreased LL and increased thoracolumbar and thoracic kyphosis (TK) are hallmarks of the aging human spine, and the prevalence of spinal deformity is increasing in the elderly population as people live longer. ${ }^{16,43}$ Degenerative sagittal imbalance in the lumbar spine can refer to fixed sagittal imbalance, ${ }^{7,8}$ lumbar degenerative kyphosis, ${ }^{44}$ primary sagittal deformity, ${ }^{47}$ or degenerative flat back. ${ }^{28,29}$ The umbrella term "primary degenerative sagittal imbalance" (PDSI) covers all degenerative sagittal misalignments of the whole spine and back muscle wasting associated with such misalignments. ${ }^{28}$ Fixed sagittal imbalance, a syndrome in which the patient is unable to stand erect without flexing the knees and hips, can be considered a severe form of PDSI. ${ }^{7,8}$ In those with lumbar degenerative kyphosis, which is known as an elderly female farmer's disease in rural areas, especially in Korea and Japan, degeneration is regarded as the main pathogenesis. ${ }^{18}$ As life expectancy continues to increase, PDSI is being diagnosed in a higher number of elderly people., , $, 16,23,28^{2}$

Patients in whom PDSI is diagnosed are usually elderly and typically show multilevel disc and facet degeneration and hypertrophy in the lower lumbar spine, poor bone quality, and atrophy and fatty degeneration of the psoas and paraspinal extensor muscles. ${ }^{45}$ Therefore, conservative therapy, such as exercise and physiotherapy, is recommended as first-line treatment. ${ }^{34}$ However, surgical treatment of PDSI should be considered for patients who complain of intractable pain in the lower back and loss of lordosis and who experience no response to conservative management. ${ }^{30,33,34}$ Significant improvements in patient outcome after surgical treatment of spinal deformity have been achieved with the introduction of spinal fusion and implants for stabilization of the spine. ${ }^{42}$ Nevertheless, deformity-correction surgery is still a challenging and complex procedure with high complication rates. ${ }^{35,42}$ Because of the high risk associated with this type of surgery, the poor musculoskeletal condition typically found in such patients, and precarious documented evidence, consensus regarding the effectiveness of deformity correction for PDSI has not yet been reached. Moreover, spine surgeons are under increasing pressure to demonstrate the clinical and costeffectiveness of the treatment, because spine care-related expenditures, which are typically high, are on the rise. ${ }^{46}$

The aim of the present study was to collate the available evidence on the effectiveness of deformity correction in patients with PDSI. To this end, we used meta-regression to analyze the relation between sufficient curve correction and clinical success.

\section{Methods}

\section{Search Strategy and Selection Criteria}

We performed a meta-analysis of clinical studies in which clinical outcomes and radiological changes after deformity-correction surgery in cases of PDSI were described. Our study followed the PRISMA (Preferred Reporting Items for Systematic Reviews and Meta-Analyses) guidelines. We searched all records in the PubMed, Em- base, Web of Science, and Cochrane databases published up to April 19, 2016. The key words for the search were "degenerative and sagittal imbalance," "degenerative and flat-back," "lumbar degenerative kyphosis," and their synonyms. The reference lists of relevant articles found in the search were reviewed. We imposed no language restrictions on study eligibility. Data extraction and quality assessment were performed independently, and consensus was achieved for all data. Study results were compared with those in eliminated duplicate reports on the same patients, which sometimes required contact with the authors of a study.

\section{Eligibility Criteria}

A clinical study fulfilled the criteria to be included in our meta-analysis if its population consisted of adults (aged $\geq 18$ years), degenerative sagittal imbalance and its surgical outcomes were assessed, and its results were provided as means \pm standard deviations. In the case of overlapping study populations, we used the study with the largest population. We excluded case reports, biomechanical studies, cadaveric studies, review articles, letters, editorials, abstracts, interim reports, and commentaries. In addition, studies that enrolled patients with a neuromuscular deformity, iatrogenic sagittal imbalance, scoliosis, kyphoscoliosis, trauma, ankylosing spondylitis, or tumors were excluded. We performed analyses within each study cohort first and then performed meta-analyses across all studies using random-effects models.

The following aspects were recorded from each study included in our analysis: scoring systems used and grades reported, total number of patients, male/female ratio, mean age, study period, follow-up duration, country of origin of the patients, and data regarding complications. The outcomes of interest were improvement of clinical outcome scores and maintenance of spinopelvic parameters. The scores for the Oswestry Disability Index (ODI) ${ }^{14}$ and visual analog scale (VAS) ${ }^{39}$ for back pain were evaluated as clinical outcomes, because they were used most commonly in the studies reviewed. The overall treatment effect was compared with its minimum clinically important difference (MCID), defined as the smallest difference perceived by the average patient. When the magnitude of the treatment effect equaled or exceeded the MCID, we considered the treatment to have improved clinical outcomes substantially. ${ }^{17}$ The reference MCIDs used in our study were 15 for ODI values and 3 for back pain VAS scores. ${ }^{36}$

The spinopelvic parameters evaluated were LL, TK, C-7 sagittal vertical axis (SVA), and pelvic tilt (PT). The values of these parameters reported from the included studies, which are indicative of the overall effects of the treatment, were compared against previously reported age-adjusted reference ranges in elderly populations; the reference ranges/values are $-45^{\circ}$ to $-75^{\circ}$ for $\mathrm{LL}, 40^{\circ}$ to $60^{\circ}$ for $\mathrm{TK}, \leq 75 \mathrm{~mm}$ for $\mathrm{SVA}$, and $10^{\circ}$ to $25^{\circ}$ for PT..$^{3,15}$, $26,29,48$ Data regarding the frequency and nature of complications after deformity-correction surgery also were collected. Complications included pseudarthrosis and proximal junctional kyphosis (PJK), which typically result in fractures, subluxations, and long sweeping kyphosis above the fusion. ${ }^{13}$ 


\section{Statistical Analysis}

The pooled results were analyzed by calculating the effect size based on the mean difference using the software Comprehensive Meta-analysis 3.0 (Biostat). The results from each study included in our meta-analysis were weighted by the inverse of the variance of the results for that study, which accounted for both within- and betweenstudy errors. To assess the heterogeneity of the results of individual studies, we used the Cochran Q test and the Higgins $\mathrm{I}^{2}$ statistic $\left(\mathrm{I}^{2}>50 \%\right.$ was used as a threshold to indicate significant heterogeneity). A random-effects or fixed-effects model was used, depending on the heterogeneity of each study included in the analysis. We assessed publication bias by visual inspection of funnel plots and by calculation of 2-tailed $\mathrm{p}$ values for the Egger intercept. Sensitivity analysis was performed by eliminating each study from the pool and determining whether the results of the statistical analysis changed. Meta-regression models were built using a moment-based method for selection of random effects. The models were used to explore the effect of LL correction in terms of clinical improvement. Results are expressed as means and 95\% CIs. All tests were 2 -tailed, and a p value $<0.05$ was deemed significant.

\section{Results}

\section{Search Results for Relevant Studies}

An initial literature search using the chosen subject headings identified 117 studies in PubMed, 168 in Embase, 141 in Web of Science, and 3 in the Cochrane Central
Register of Controlled Trials. Among these 429 studies, 88 were duplicates and were thus excluded. Also, 36 of the 341 remaining papers were excluded from our analysis for being a case report, review article, letter, technical note, or patent. After screening titles and abstracts, 147 studies about secondary kyphosis, 67 studies including patients with scoliosis, 49 studies of cervical spine disease, and 6 basic research studies also were excluded. The remaining 36 studies were subjected to a full-text review, and another 26 were excluded. These 26 articles were excluded because the studies used a mixed group, including patients with other degenerative diseases $(n=7)$, included no description of the standard deviation $(n=7)$, included duplication of enrolled patients $(n=6)$, used an incompatible evaluation tool $(\mathrm{n}=5)$, or reported a follow-up duration that was too short $(n=1)$. Therefore, a total of 10 studies were included in our meta-analysis. Detailed results of the selection process are shown in Fig. 1.

\section{Risk of Bias Within Studies}

Follow-up duration was described in terms of minimum or mean. Although the mean follow-up duration in each study was 24 months or longer, the minimum followup duration was 24 months in 7 studies, 18 months in 1 study, ${ }^{23}$ and 12 months in 2 studies $^{9,31}$ (Table 1). Reference ranges for spinopelvic parameters vary depending on the age group. In our study, we used reference ranges for the geriatric age group (>60 years). However, the mean age in the Burkett et al. ${ }^{9}$ study was 57.7 years, whereas the mean age in the other studies was greater than 60 years.

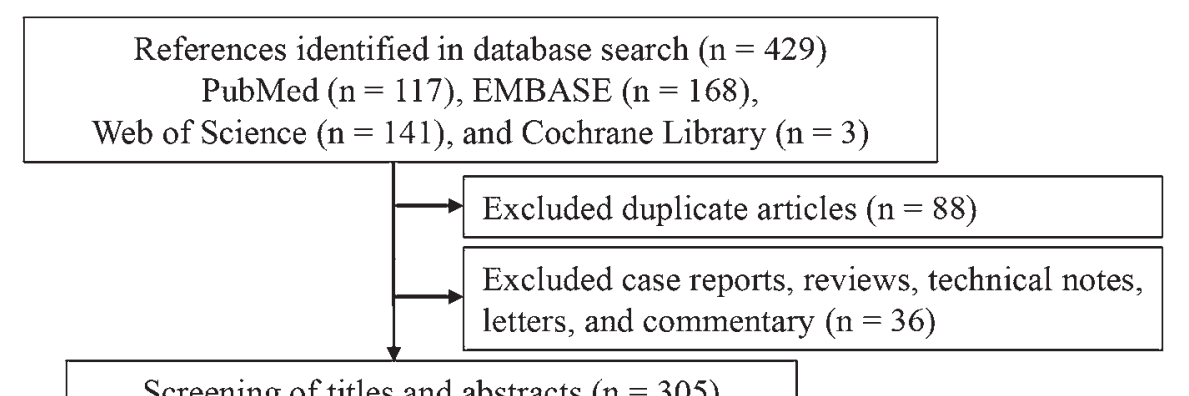

Screening of titles and abstracts $(n=305)$

\begin{tabular}{|l|l|} 
& $\begin{array}{l}\text { Secondary kyphosis due to systemic disease }(\mathrm{n}=147) \\
\text { Enrolled scoliosis patients }(\mathrm{n}=67) \\
\text { Cervical spinal disease }(\mathrm{n}=49) \\
\text { No clinical study }(\mathrm{n}=6)\end{array}$ \\
\hline
\end{tabular}

Full-text review $(\mathrm{n}=36)$

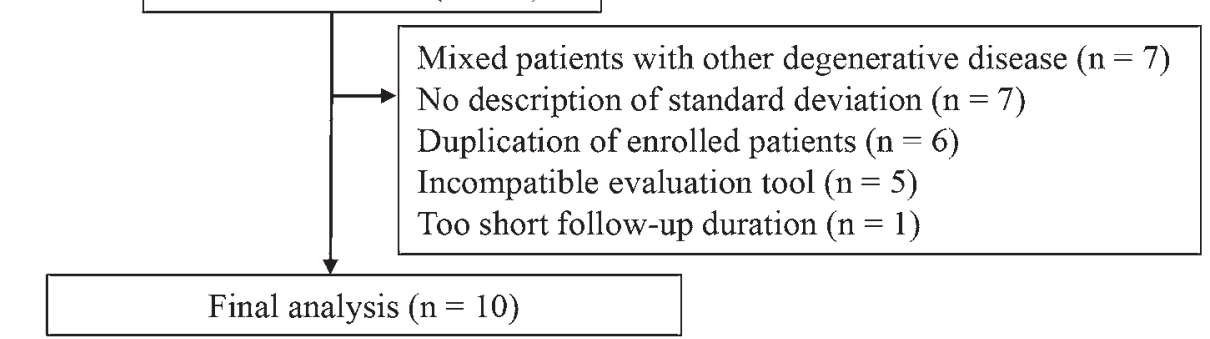

FIG. 1. Flow diagram showing the identification of relevant studies on deformity-correction surgery in patients with degenerative sagittal imbalance. 
TABLE 1. Characteristics of studies included in the meta-analysis

\begin{tabular}{|c|c|c|c|c|c|c|c|}
\hline Authors \& Year & Region & Study Period & No. of Pts & No. of Female Pts & Mean Age (yrs) & Mean Fusion Level & FU in $\mathrm{Mos}^{*}$ \\
\hline Jang et al., 2009 & Korea & ND & 53 & 51 & 62.0 & ND & $\geq 24$ \\
\hline Xie et al., 2009 & China & $2001-2008$ & 20 & 19 & 64.0 & ND & $\geq 24$ \\
\hline Rose et al., 2009 & USA & 1995-2004 & 15 & 13 & 63.3 & 9.2 & $\geq 24$ \\
\hline Lee et al., 2009 & Korea & $1996-2006$ & 33 & 33 & 61.2 & 4.9 & $\geq 12(34.7)$ \\
\hline Kim et al., $2010(G)$ & Korea & $2004-2007$ & 16 & 16 & 67.0 & ND & \multirow{2}{*}{$\geq 18(24.4)$} \\
\hline Kim et al., 2010 (B) & Korea & $2004-2007$ & 9 & 9 & 64.0 & ND & \\
\hline Lee et al., 2011 & Korea & $2008-2012$ & 23 & 23 & 63.6 & 7.7 & $\geq 24$ \\
\hline Burkett et al., 2013 (P) & USA & $2003-2008$ & 22 & 17 & 58.7 & ND & $\geq 12(41.8)$ \\
\hline Burkett et al., 2013 (AP) & USA & $2003-2008$ & 11 & 11 & 55.7 & ND & $\geq 12(47.7)$ \\
\hline Cho et al., 2013 & Korea & ND & 34 & 32 & 63.9 & 8.1 & $\geq 24$ \\
\hline Kim et al., 2015 & Korea & $2000-2006$ & 40 & 37 & 65.1 & 6.9 & $\geq 24$ \\
\hline Lee et al., 2016 & Korea & 2004-2010 & 51 & 48 & 66.5 & 6.6 & $\geq 24$ \\
\hline Total (\%) or average & & & 327 & $309(94.5)$ & 62.9 & 7.0 & \\
\hline
\end{tabular}

$\mathrm{AP}=$ combined (anterior-posterior or posterior-anterior-posterior) approach group; $\mathrm{B}=$ bad clinical outcome group; FU = follow-up; $\mathrm{G}=$ good clinical outcome group; ND $=$ not described; $P$ = posterior approach only group; $P$ ts = patients.

* Values in parentheses are means.

In addition, the study by Kim et al. ${ }^{23}$ included an 18-yearold patient. Although this patient satisfied the criteria for inclusion in terms of adult age ( $\geq 18$ years), it is highly likely that degenerative spinal disease was not the main issue in that particular case, because PDSI usually occurs in elderly people. Therefore, some patients in the Kim et al. study might not have had degenerative spinal disease. In the study by Rose et al., ${ }^{37} 15$ of 40 patients had degenerative sagittal imbalance, and our analysis included the results for only those 15 patients.

\section{Results of Individual Studies and Synthesis of Results}

Table 1 summarizes the key information extracted from the 10 studies included in this analysis. The selected studies included 327 participants. The countries in which the studies were conducted included the Republic of Korea $(n=7)$, the United States $(n=2)$, and China $(n=1)$. The average age of the patients was 62.9 years, and female patients accounted for $94.5 \%$ of all enrolled patients. The mean number of fused segments was 7.0 (range 4.9-9.2). In each study, the mean follow-up duration was 24 months or more. The surgical indications that the included studies addressed were adult age ( $\geq 18$ years), loss of LL, a C-7 SVA of $\geq 50 \mathrm{~mm}$, and a PT of $\geq 25^{\circ}$.

Clinical outcomes, evaluated in terms of values for ODI and VAS of back pain, were found to have improved at final follow-up, approximately 2 years after deformitycorrection surgery. The ODI value at follow-up decreased by 18.11 (95\% CI 10.99-25.23) from its baseline value of 37.29 (Fig. 2A). Although the mean difference in ODI values exceeded the MCID of ODI values (15 points on a 50-point scale), the lower limit of the $95 \%$ CI encompassed the MCID. We estimated that approximately $80.1 \%$ of the patients achieved an improvement in their ODI scores above the MCID, assuming that the values of the change in ODI had a standard normal distribution. The VAS score at final follow-up decreased by 4.15 points (95\% CI 3.48-4.82) from its baseline of 6.70. Both the mean difference and 95\% CI of the VAS scores greatly exceeded the MCID of VAS scores, which was 3 points on a 10-point scale (Fig. 2B).

An overview of the spinopelvic parameters analyzed is provided in Table 2 . The mean LL angles were $-3.95^{\circ}$ $\left(95 \% \mathrm{CI}-13.30^{\circ}\right.$ to $\left.5.40^{\circ}\right)$ at baseline and $-38.60^{\circ}(95 \%$ CI $-44.19^{\circ}$ to $-33.01^{\circ}$ ) (Fig. 3A) at the final follow-up. Decompensation of LL accounted for $5.82^{\circ}$ (95\% CI $3.35^{\circ}-$ $8.29^{\circ}$ ) of the difference between the immediate postoperative state and the state at a mean of 2 years after surgery (Fig. 3B). The mean TK angle at baseline was $16.59^{\circ}$ $\left(95 \%\right.$ CI $\left.7.36^{\circ}-25.83^{\circ}\right)$, which is not substantially different from the reference range of TK values $\left(40^{\circ}-60^{\circ}\right)$. At the 2-year follow-up, the mean TK angle was $31.10^{\circ}(95 \%$ CI $24.67^{\circ}-37.53^{\circ}$ ) (Fig. 4A), and decompensation of TK was $4.70^{\circ}\left(95 \%\right.$ CI $\left.0.59^{\circ}-8.81^{\circ}\right)$ (Fig. 4B). The mean C-7 SVA at baseline was $174.59 \mathrm{~mm}(95 \%$ CI 133.16-216.02 $\mathrm{mm})$, which is very far from the reference value for SVA $(\leq 75 \mathrm{~mm})$. The mean C-7 SVA at the 2-year follow-up was $65.00 \mathrm{~mm}$ (95\% CI 35.27-94.72 mm) (Fig. 5A), and decompensation of C-7 SVA was 38.20 mm (95\% CI 7.06$69.33 \mathrm{~mm}$ ) (Fig. 5B). The mean PT at baseline was $38.23^{\circ}$ $\left(95 \%\right.$ CI $\left.35.20^{\circ}-41.25^{\circ}\right)$, which is far from the reference range of values for $\mathrm{PT}\left(10^{\circ}-25^{\circ}\right)$. The mean $\mathrm{PT}$ at the final measurement was $30.74^{\circ}$ (95\% CI $23.45^{\circ}-38.04^{\circ}$ ) (Fig. 6).

PJK occurred in 27 (23.7\%) of 114 patients for whom data were available, and 2 patients (7.4\%) underwent revision surgery. Pseudarthrosis occurred in 12 (12.8\%) of 94 patients for whom data were available, and 5 patients (5.3\%) underwent revision surgery.

\section{Sensitivity and Meta-Regression Analyses}

Single elimination of each study did not affect the overall results of the meta-analysis significantly. The result of the Egger test for C-7 SVA was $7.26(p=0.04)$, and the funnel plot of C-7 SVA revealed substantial asymmetry (Table 3), which might indicate an underpowered analysis. The funnel plots of the other parameters were symmet- 


\begin{tabular}{|c|c|c|c|c|c|c|c|}
\hline & $\begin{array}{l}\text { erence } \\
\text { means }\end{array}$ & $\begin{array}{c}\text { Standard } \\
\text { error }\end{array}$ & Variance & $\begin{array}{l}\text { Lower } \\
\text { limit }\end{array}$ & $\begin{array}{c}\text { Upper } \\
\text { limit }\end{array}$ & Z-Value & $\begin{array}{r}\text { Relati } \\
\text { weig }\end{array}$ \\
\hline A. Mean diff & ence & & & & ility in & & (I) \\
\hline Jang, JS et al. $2009^{19}$ & 11.25 & 0.879 & 0.773 & 9.527 & 12.973 & 12.797 & \\
\hline Rose, PS et al. 2009 & 15.60 & 4.524 & 20.463 & 6.734 & 24.466 & 3.449 & \\
\hline Xie, J et al. 2009 & 12.70 & 1.214 & 1.474 & 10.320 & 15.080 & 10.460 & \\
\hline Cho, KJ et al. 2013 & 25.60 & 1.753 & 3.072 & 22.165 & 29.035 & 14.606 & \\
\hline Lee, JH et al. 2016 & 25.00 & 0.853 & 0.727 & 23.329 & 26.671 & 29.316 & \\
\hline Summary & 18.11 & 3.633 & 13.200 & 10.989 & 25.231 & 4.985 & \\
\hline
\end{tabular}

\begin{tabular}{|c|c|c|c|c|c|c|}
\hline Jang, JS et al. $2009^{19}$ & 5.00 & 0.309 & 0.096 & 4.394 & 5.606 & 16.178 \\
\hline Xie, J et al. 2009 & 4.70 & 0.318 & 0.101 & 4.078 & 5.322 & 14.802 \\
\hline Lee, JC et al. 2009 & 4.18 & 0.409 & 0.167 & 3.378 & 4.982 & 10.218 \\
\hline Kim, WJ et al.(G) 2010 & 3.94 & 0.245 & 0.060 & 3.460 & 4.420 & 16.082 \\
\hline Kim, WJ et al.(B) 2010 & 2.78 & 0.427 & 0.182 & 1.944 & 3.616 & 6.516 \\
\hline Summary & 4.15 & 0.342 & 0.117 & 3.482 & 4.822 & 12.140 \\
\hline
\end{tabular}

2

(1)
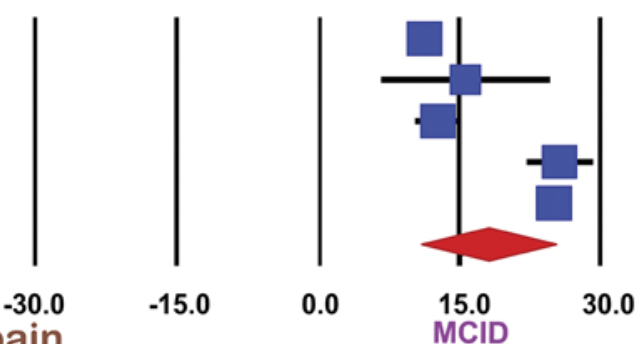

\section{pain}

\begin{tabular}{l|}
20.78 \\
20.59 \\
8.43 \\
2.18 \\
8.01
\end{tabular}

$-6.00$
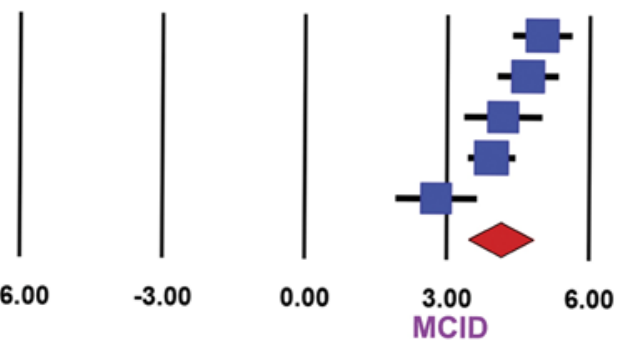

FIG. 2. Changes in back pain evaluated by using ODI and VAS scores after deformity-correction surgery in patients with degenerative sagittal imbalance. The MCIDs in ODI and VAS values are 15 and 3, respectively. At least $95 \%$ of the patients showed a treatment effect that exceeded the MCID for the VAS back pain scores but not for the ODI scores. Figure is available in color online only.

ric, which indicated an absence of substantial publication bias within the studies. The Egger test results for the other items indicated that no substantial publication bias in the data set existed (Table 3).

Univariate meta-regression analysis revealed that the change in LL after deformity correction was the key factor influencing the overall effect size for studies that investigated postoperative ODI improvement $(\mathrm{p}=0.004)$ (Fig. $7)$. The squared correlation coefficient $\left(\mathrm{R}^{2}\right)$ value for this model was 0.84 , which suggests a considerable relationship between LL correction and ODI improvement. Although we found a substantial relationship between TK and ODI change $(\mathrm{p}=0.002)$, the increase in TK was not achieved directly via deformity correction but, rather, indirectly in response to an increase in LL. Results of meta-regression indicated no clear relationship between the SVA change and ODI change $(p=0.69)$. We found insufficient data for performing meta-regression analyses to determine the relationship between other variables and VAS score changes.

\section{Discussion}

Deformity correction for PDSI is highly individualized, and opposing views pervade the field of spine surgery in terms of the clinical and cost-effectiveness of this type of surgery. The results of our meta-analysis reveal that deformity-correction surgery improves back pain significantly, although ODI values did not indicate significant improvement. In the meta-regression analyses, higher LL achievement after deformity correction predicted better ODI improvement. Achieving sufficient LL correction via surgery might be important for achieving clinical success.
In the 2-year follow-up period, decompensation of spinopelvic parameters was not substantial. PJK can occur as a complication of deformity correction in one-fourth of the reported cases.

The mean baseline ODI and VAS values were 37.29 and 6.70, respectively, which suggests that patients with PDSI who underwent deformity-correction surgery reported very severe back pain and considerable disability. Our meta-analysis revealed that deformity-correction surgery substantially relieved back pain for approximately 2 years after the surgery, which is an encouraging result in the context of previous reports for the outcome of patients with PDSI who underwent nonoperative treatment and did not experience significant improvement in back or leg pain. ${ }^{6,41}$ The International Spine Study Group reported that patients who were treated nonoperatively for adult spinal deformity gained an average 0.27 MCID by the 1-year follow-up visit; of the patients who experienced significant improvement (defined as $>1$ MCID), a 24\% reduction in pain was revealed..$^{40}$ Thus, it was concluded that nonoperative treatment is a viable option for certain patients with adult spinal deformity of the mildest degree for whom surgery can be avoided; in contrast, patients with the worst baseline scores might be advised to proceed directly to surgery and avoid the unnecessary costs and prolonged discomfort of a futile nonoperative trial. ${ }^{40} \mathrm{With}$ respect to the outcome of limited surgery, a previous report indicated that the interbody fusion of short segments is ineffective at restoring sagittal balance. In patients with PDSI, alternative surgical techniques, such as corrective osteotomy, should be considered before performing limited surgery. ${ }^{12}$

Although we found that ODI values improved after 


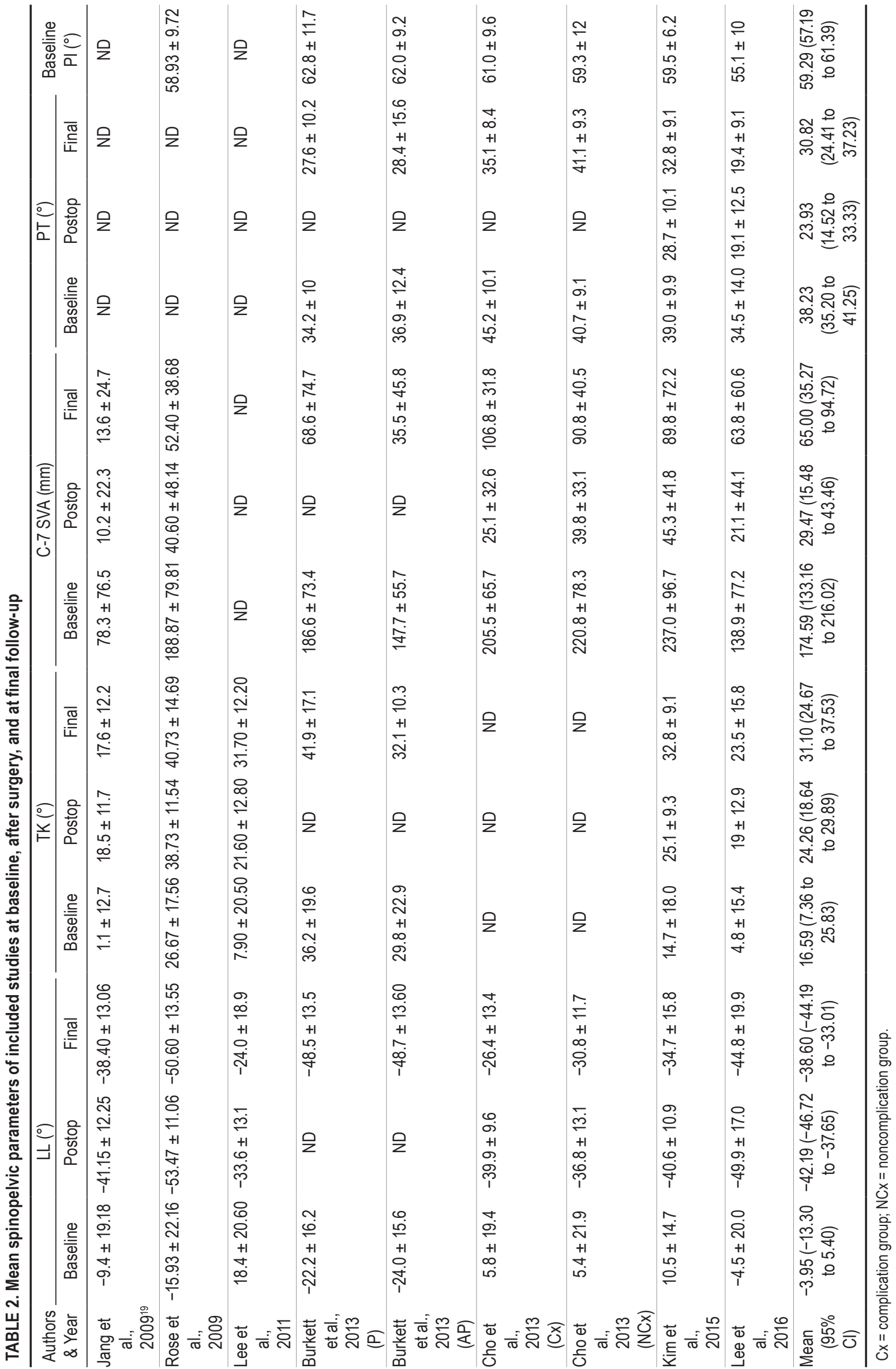




\section{A. Lumbar lordosis (LL) in 2-year follow-up}

\section{Study name}

\section{Statistics for each study}

\begin{tabular}{rrrrrrr} 
Mean & $\begin{array}{c}\text { Standard } \\
\text { error }\end{array}$ & \multicolumn{2}{c}{$\begin{array}{c}\text { Variance } \\
\text { limit }\end{array}$} & $\begin{array}{c}\text { Upper } \\
\text { limit }\end{array}$ & $\begin{array}{r}\text { Z-Value } \\
\text { Relative } \\
\text { weight }\end{array}$ \\
-38.400 & 1.794 & 3.218 & -41.916 & -34.884 & -21.406 & 12.24 \\
-50.600 & 3.499 & 12.240 & -57.457 & -43.743 & -14.463 & 10.77 \\
-24.000 & 3.941 & 15.531 & -31.724 & -16.276 & -6.090 & 10.32 \\
-48.500 & 2.878 & 8.284 & -54.141 & -42.859 & -16.851 & 11.37 \\
-48.700 & 4.101 & 16.815 & -56.737 & -40.663 & -11.876 & 10.16 \\
-26.400 & 4.040 & 16.324 & $-34.319-18.481$ & -6.534 & 10.22 \\
-30.800 & 2.440 & 5.952 & -35.582 & -26.018 & -12.625 & 11.75 \\
-34.700 & 2.498 & 6.241 & -39.596 & -29.804 & -13.890 & 11.71 \\
-44.800 & 2.787 & 7.765 & -50.262 & -39.338 & -16.077 & 11.45 \\
-38.603 & 2.852 & 8.131 & -44.192 & -33.014 & -13.537 &
\end{tabular}

Mean and $95 \% \mathrm{C}$

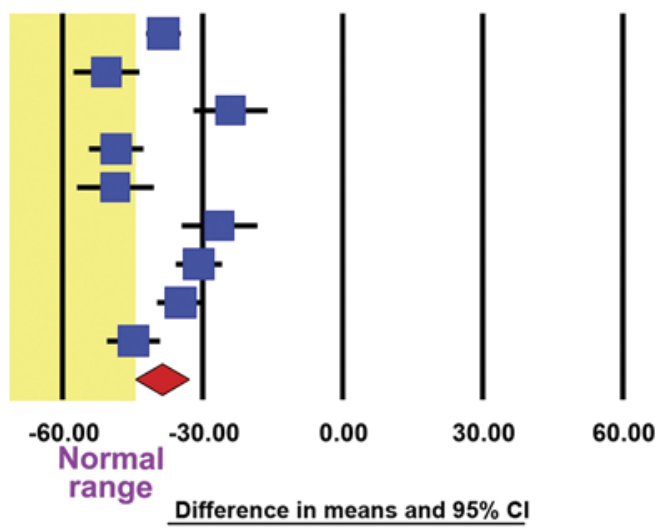

Relative

weight

22.58

11.02

9.78

9.33

14.76

17.82

14.70

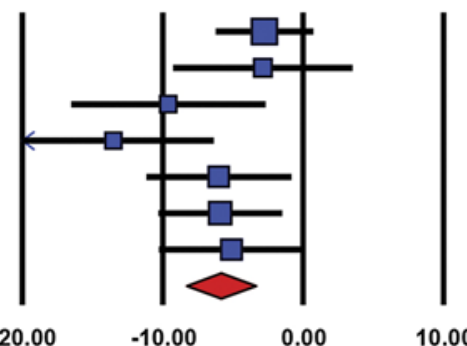

10.00

FIG. 3. The mean $L L$ angle at the final follow-up was $-38.61^{\circ}$. The reference range for $L L$ angle in the elderly population is $-45^{\circ}$ to $75^{\circ}$. Approximately 2 years after surgery, the mean decompensation was $5.82^{\circ}$. Figure is available in color online only.

deformity-correction surgery, the lowest limit of the $95 \%$ CI for ODI change did not exceed 1 MCID. However, one should not conclude hastily that deformity-correction surgery had little effect on functional outcomes. The patients who experienced significant ODI improvement ( $\geq 1$ MCID) accounted for $80.1 \%$ of the patients analyzed. The metaregression analysis revealed that ODI improvement was closely related with sufficient correction of LL. A previous study found that its group of patients with sufficient LL correction had substantially higher ODI improvement than its group of patients with insufficient LL correction. ${ }^{32}$ For this reason, another paper introduced the rule $\mathrm{LL}=-$ (pelvic incidence $[\mathrm{PI}]+10^{\circ}$ ) as an easy way to calculate sagittal correction preoperatively and a very effective method of planning for LL correction and good alignment. ${ }^{2}$ Although we did not have access to the actual spinopelvic parameter values for each patient, a brief examination of the summary of LL values from all 5 studies that reported both LL and PI indicated that the above-mentioned criterion for LL correction was not satisfied., ${ }^{9,10,22,32,37}$ This insufficient correction of LL is likely the reason why ODIs were not improved substantially after deformity-correction surgery.

PT is a representative positional parameter that reflects compensation for spinal deformity. One way to compensate for a positive shift in spinal sagittal alignment is for the pelvis to rotate into retroversion (increased PT), which leads to hip hyperextension or a decrease in the anterior coverage of the hip. ${ }^{27}$ SVA is correlated closely with PT, and thus, restoring the PT to within the reference range is important for restoring ambulatory function by improving the range of hip extension. ${ }^{27}$ In our analysis, the mean PT decreased by $7.41^{\circ}$ after surgery, even though the mean LL angle increased by $34.65^{\circ}$. Surgery that results in sufficient LL correction (including correction of pelvic compensation) can succeed in restoring PT and SVA to within the reference range, which would likely result in substantial ODI improvement.

In addition to the LL correction achieved at the postoperative state, prevention of decompensation is another major goal of deformity-correction surgery. ${ }^{5,11,25,32}$ Sagittal plane decompensation is a key factor in adverse outcomes. ${ }^{9}$ Our meta-analysis revealed that decompensation during the follow-up period resulted in a $5.82^{\circ}$ decrease in LL, a $4.70^{\circ}$ increase in TK, and a $38.9-\mathrm{mm}$ increase in SVA, which indicates mild decompensation of spinopelvic parameters. Results of a previous study suggested that postoperative improvement in LL played a key role in restoring normal sagittal balance and preventing the occurrence of decompensation. ${ }^{25}$ The authors insisted that a high postoperative C-7 SVA $(\geq 50 \mathrm{~mm})$ and an LL-TK angle of $<10^{\circ}$ at 8 weeks after the surgery represent risk factors for sagittal thoracic decompensation. ${ }^{25}$ In our meta-analysis, all the studies reported C-7 SVAs of $<50 \mathrm{~mm}$ and LL-TK angles of $\geq 10^{\circ}$ in the immediate postoperative state, ${ }^{19,21,32,33,37}$ which indicates that sufficient LL correction was achieved to prevent substantial decompensation; 
A. Thoracic kyphosis (TK) in 2-year follow-up Study name Statistics for each study

\begin{tabular}{lrrrrrrr} 
& \multicolumn{3}{c}{$\begin{array}{c}\text { Standard } \\
\text { Mean }\end{array}$} & $\begin{array}{c}\text { error } \\
\text { Variance }\end{array}$ & $\begin{array}{c}\text { Lower } \\
\text { limit }\end{array}$ & $\begin{array}{c}\text { Upper } \\
\text { limit }\end{array}$ & $\begin{array}{r}\text { Z-Value } \\
\text { Jelative } \\
\text { weight }\end{array}$ \\
Rong, JS et al. 200919 & 17.600 & 1.676 & 2.808 & 14.315 & 20.885 & 10.502 & 15.21 \\
Rose, PS et al. 2009 & 40.730 & 3.793 & 14.386 & 33.296 & 48.164 & 10.738 & 13.07 \\
Lee, SH et al. 2011 & 31.700 & 2.544 & 6.471 & 26.714 & 36.686 & 12.461 & 14.46 \\
Burkett, B et al. (P)2013 & 41.900 & 3.646 & 13.291 & 34.754 & 49.046 & 11.493 & 13.25 \\
Burkett, B et al. (AP)201332.100 & 3.106 & 9.645 & 26.013 & 38.187 & 10.336 & 13.87 \\
Kim, KT et al. 2015 & 32.800 & 1.439 & 2.070 & 29.980 & 35.620 & 22.796 & 15.37 \\
Lee, JH et al. 2016 & 23.500 & 2.212 & 4.895 & 19.164 & 27.836 & 10.622 & 14.77 \\
$\quad$ Summary & 31.100 & 3.278 & 10.748 & 24.674 & 37.525 & 9.486 &
\end{tabular}

\section{B. Mean difference in TK decompensation Study name}

Mean and $95 \% \mathrm{Cl}$
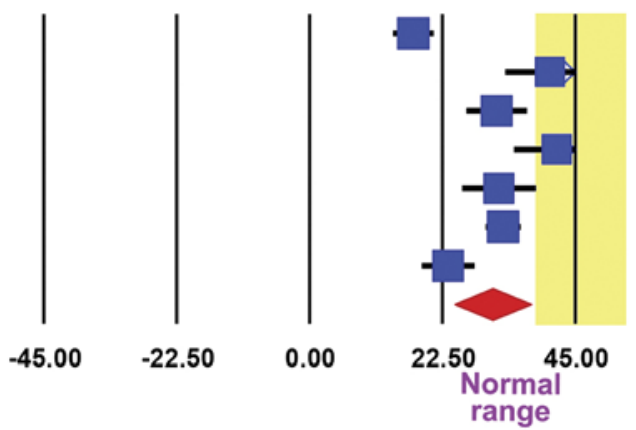

Difference in means and $95 \% \mathrm{Cl}$

\section{Relative}

Difference

Lower Upper

limit limit

Z-Value

\subsection{7}

$-0.578$

22.39

Jang, JS et al. $2009^{19} \quad 0.83$

$\begin{array}{llll}1.637 & 2.681 & -2.379 & 4.039\end{array}$

3.457

$\begin{array}{lll}11.953 & -8.776 \quad 4.776\end{array}$

$-0.578$

15.21

Lee, $\mathrm{SH}$ et al. 2011

$-10.10$

2.609

$6.804-15.213-4.987$

$\begin{array}{lll}2.116 & -10.551 & -4.849\end{array}$

$-5.293$

18.51

Kim, KT et al. 2015

-7.70
-4.50

2.040

$\begin{array}{lll}4.162 & -8.499 & -0.501\end{array}$

$-2.206$

23.06

20.82

Summary

$\begin{array}{lllll}4.400 & -8.812 & -0.589 & -2.241\end{array}$
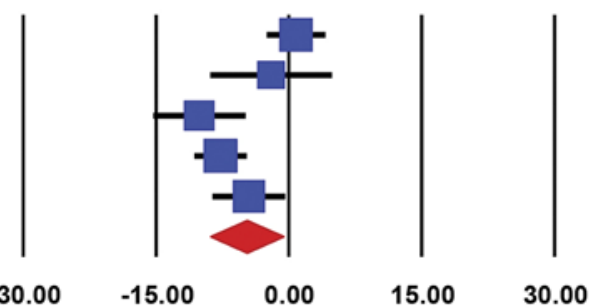

FIG. 4. The mean TK angle at final follow-up was $31.10^{\circ}$. The reference range for TK angle in the elderly population is $40^{\circ}-60^{\circ}$. Approximately 2 years after surgery, the mean decompensation was $4.70^{\circ}$. Figure is available in color online only.

A. C7 sagittal vertical axis (SVA) in 2-year follow-up Study name Statistics for each study

Mean
13.60
52.40
68.60
35.50
106.80
90.80
89.80
63.80
65.00

Standard Lower Upper rror Variance limit limit Z-Value weight

Jang, JS et al. $2009^{19}$

Rose, PS et al. 2009

3.39

9.99

15.93

11.51$$
\begin{array}{ll}
6.95 \quad 20.25 \\
\hline
\end{array}
$$

11.51
99.74

99.74

$\begin{array}{lll}6.95 & 20.25\end{array}$

Burkett, B (P)et al. 2013

13.81

253.64

$32.83 \quad 71.97$

Burkett, B (AP)et al. $2013 \quad 35.50$

Cho, KJ (Cx)et al. $2013 \quad 106.80$

Cho, KJ (NCx)et al. $2013 \quad 90.80$

$\mathrm{Kim}, \mathrm{KT}$ et al. 2015

Lee, JH et al. 2016

Summary

65.00

190.69

$9.59 \quad 91.93$

$8.44 \quad 71.32$

$11.42 \quad 130.32$

$8.49 \quad 72.01$

$15.17 \quad 229.99$

$37.39 \quad 99.81$

$8.43 \quad 62.57$

88.01125 .59

$\begin{array}{lll}74.25 & 107.35\end{array}$

$\begin{array}{ll}67.43 & 112.17\end{array}$

\begin{tabular}{ll}
$47.17 \quad 80.43$ \\
\hline
\end{tabular}

$35.27 \quad 94.72$

4.01
5.25
4.31
2.57
11.14
10.75
7.87
7.52
4.29

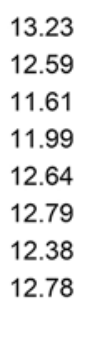

13.23
12.59
11.61
11.99
12.64
12.79
12.38
12.78

B. Mean difference in C7 SVA decompensation Study name

\section{Statistics for each study}

\begin{tabular}{|c|c|c|c|c|c|c|c|}
\hline & $\begin{array}{l}\text { Difference } \\
\text { in means }\end{array}$ & $\begin{array}{l}\text { Standard } \\
\text { error }\end{array}$ & Variance & $\begin{array}{c}\text { Lower } \\
\text { limit }\end{array}$ & $\begin{array}{l}\text { Upper } \\
\text { limit }\end{array}$ & Z-Value & $\begin{array}{r}\text { Relative } \\
\text { weight }\end{array}$ \\
\hline Jang, JS et al. $2009^{19}$ & -3.39 & 3.236 & 10.473 & -9.733 & 2.953 & -1.048 & 17.73 \\
\hline Rose, PS et al. 2009 & -11.80 & 11.407 & 130.125 & -34.158 & 10.558 & -1.034 & 15.83 \\
\hline Cho, KJ (Cx) et al. 2013 & -81.70 & 9.712 & 94.317 & -100.735 & -62.665 & -8.413 & 16.35 \\
\hline Cho, KJ (NCx) et al. 2013 & -51.00 & 7.788 & 60.653 & -66.264 & -35.736 & -6.549 & 16.88 \\
\hline Kim, KT et al. 2015 & -44.50 & 9.928 & 98.565 & -63.958 & -25.042 & -4.482 & 16.29 \\
\hline Lee, JH et al. 2016 & -42.70 & 7.599 & 57.750 & -57.594 & -27.806 & -5.619 & 16.93 \\
\hline Summary & -38.91 & 13.271 & 176.119 & -64.921 & -12.900 & -2.932 & \\
\hline
\end{tabular}
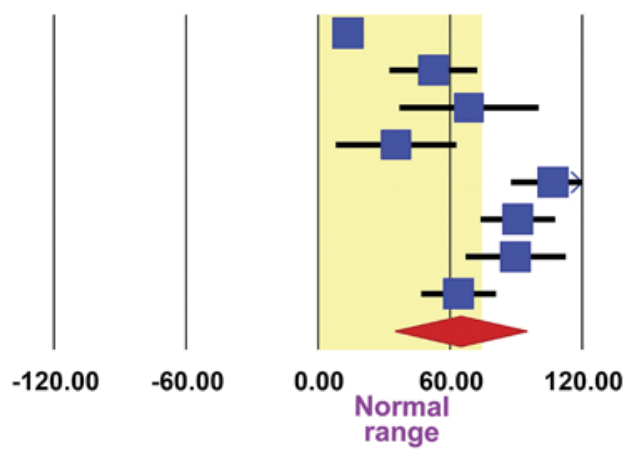

Difference in means and $95 \% \mathrm{Cl}$
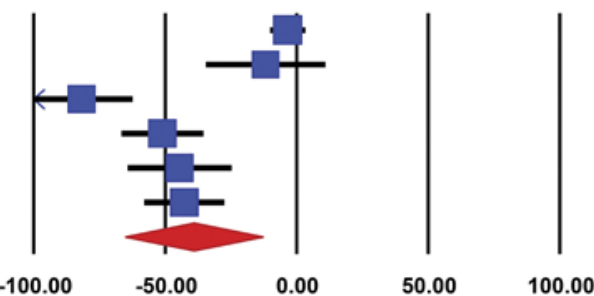

FIG. 5. The mean C-7 SVA at final follow-up was $65.00 \mathrm{~mm}$. The reference SVA in the elderly population is $\leq 75 \mathrm{~mm}$. During the follow-up period, substantial decompensation of C-7 SVA was found, and the mean SVA increased by $38.91 \mathrm{~mm}$. Figure is available in color online only. 


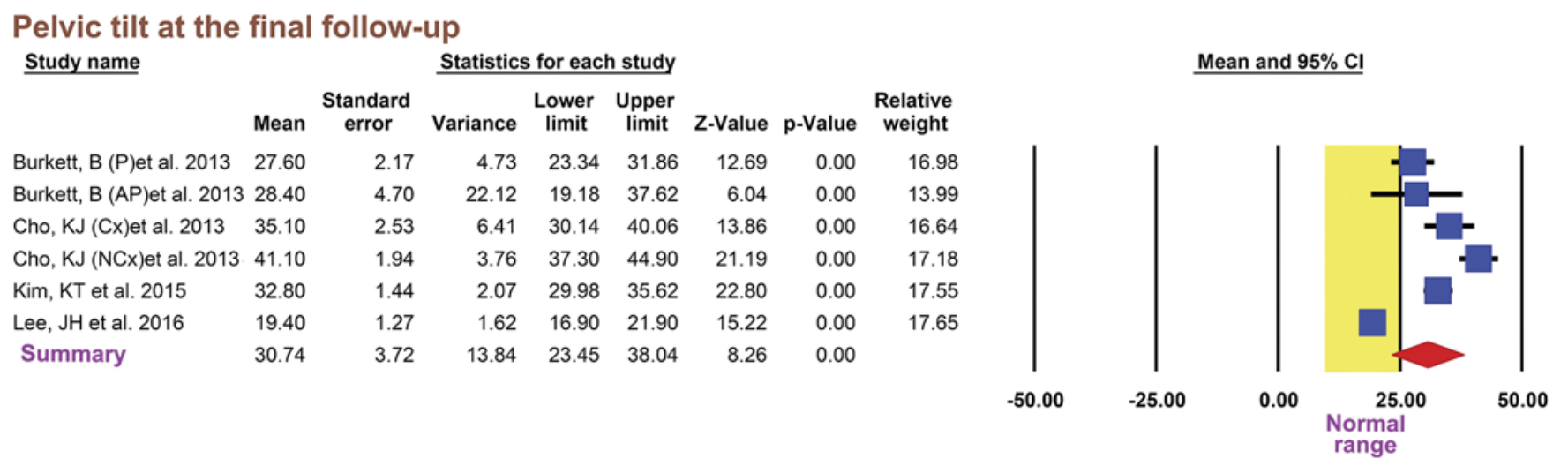

FIG. 6. The mean PT at final follow-up was $30.74^{\circ}$. The reference range for $\mathrm{PT}$ in the elderly population is $10^{\circ}-25^{\circ}$. A majority of the patients still had an abnormal PT after deformity-correction surgery. Figure is available in color online only.

this observation explains why only mild decompensation was noted 2 years after surgery.

The results of our meta-analysis show that surgically induced LL was sufficient to prevent decompensation but not sufficient to restore pelvic compensation. The decision regarding which approach is best suited for achieving sufficient LL correction in any given case resides with the surgeon and typically depends on the surgeon's experience and expertise. ${ }^{9}$ However, for achieving high LL, performing both posterior shortening and anterior release might be better than performing only posterior shortening. ${ }^{9}$ Unfortunately, we did not have sufficient data to compare the outcomes of posterior shortening to those of posterior shortening combined with anterior release. Additional studies are needed to evaluate whether sufficient LL correction can achieve substantial ODI improvement and restore PT to within the reference range in patients with PDSI.

PJK is a common radiographic finding after long spinal fusions. The authors of a previous review paper reported that their prevalence rates of PJK varied widely, from $6 \%$ to $61.7 \% . .^{13}$ Although PJK occurred in one-fourth of the patients included in our study, the incidence of severe fracture or kyphosis was low. Numerous studies found that the clinical outcomes for patients with PJK were not significantly different from those of patients without PJK; only 1 study recently indicated that adult patients with PJK experienced more pain. ${ }^{13,20} \mathrm{Kim}$ et al. ${ }^{24}$ suggested that the
Scoliosis Research Society outcome instrument is not adversely affected by PJK unless the PJK angle is $>20^{\circ}$. The prevalence of PJK after long spinal fusion for adult spinal deformity is high but less clinically significant; nonetheless, spine surgeons should try to reduce the risk for substantial PJK to prevent clinical deterioration.

Some limitations in our meta-analysis need to be acknowledged and addressed. The first limitation is that we included single-treatment-arm studies. We had intended to compare the clinical and radiological outcomes of deformity correction to those of limited surgery or nonoperative treatment. However, it was impossible to find appropriate reports for such a direct comparison of patients with PDSI. As an alternative solution, we compared the outcomes to reference MCIDs or reference ranges. It is difficult to know whether an improvement in pain with moderate improvement in the ODI might translate into clinical success. Although our approach might not have been optimal, it enabled us to provide an objective evaluation of the effectiveness of deformity correction in patients with PDSI. The second limitation is related to the heterogeneity noted in terms of surgical techniques used and patient characteristics, which might imply that the reported findings cannot be easily generalized beyond the cases studied. Various surgical approaches are used for correcting spinal deformity, and each spine surgeon takes time to plan the procedure carefully to achieve an optimal outcome in each par-

TABLE 3. Heterogeneity and publication bias test results for each item

\begin{tabular}{lccrrrrr}
\hline \multicolumn{1}{c}{ Item } & $\mathrm{Q}$ & $\mathrm{df}(\mathrm{Q})$ & $\mathrm{p}$ Value $(\mathrm{Q})$ & \multicolumn{1}{c}{$R^{2}$} & \multicolumn{1}{c}{$\tau^{2}$} & Egger Test & $\mathrm{p}$ Value (Egger; 2-tailed) \\
\hline ODI change & 24.10 & 3 & $<0.01$ & 87.55 & 0.82 & 6.73 & 0.20 \\
\hline VAS back pain score change & 11.86 & 4 & 0.02 & 66.26 & 0.33 & 2.93 & 0.13 \\
\hline LL at final FU & 91.86 & 9 & $<0.01$ & 91.20 & 71.30 & -1.31 & 0.75 \\
\hline LL decompensation & 9.540 & 6 & 0.15 & 37.10 & 4.00 & -3.44 & 0.06 \\
\hline TK at final FU & 83.17 & 6 & $<0.01$ & 92.79 & 67.85 & 4.74 & 0.30 \\
\hline TK decompensation & 20.50 & 4 & $<0.01$ & 80.49 & 0.13 & -4.19 & 0.38 \\
\hline C-7 SVA at final FU & 168.69 & 5 & 0.02 & 96.44 & 2021.03 & 7.26 & 0.04 \\
\hline C-7 SVA decompensation & 28.56 & 4 & $<0.01$ & 86.00 & 0.32 & -4.80 & 0.09 \\
\hline PT at final FU & 24.36 & 4 & $<0.01$ & 83.58 & 24.27 & -1.17 & 0.78 \\
\hline
\end{tabular}

$\mathrm{df}=$ degrees of freedom. 


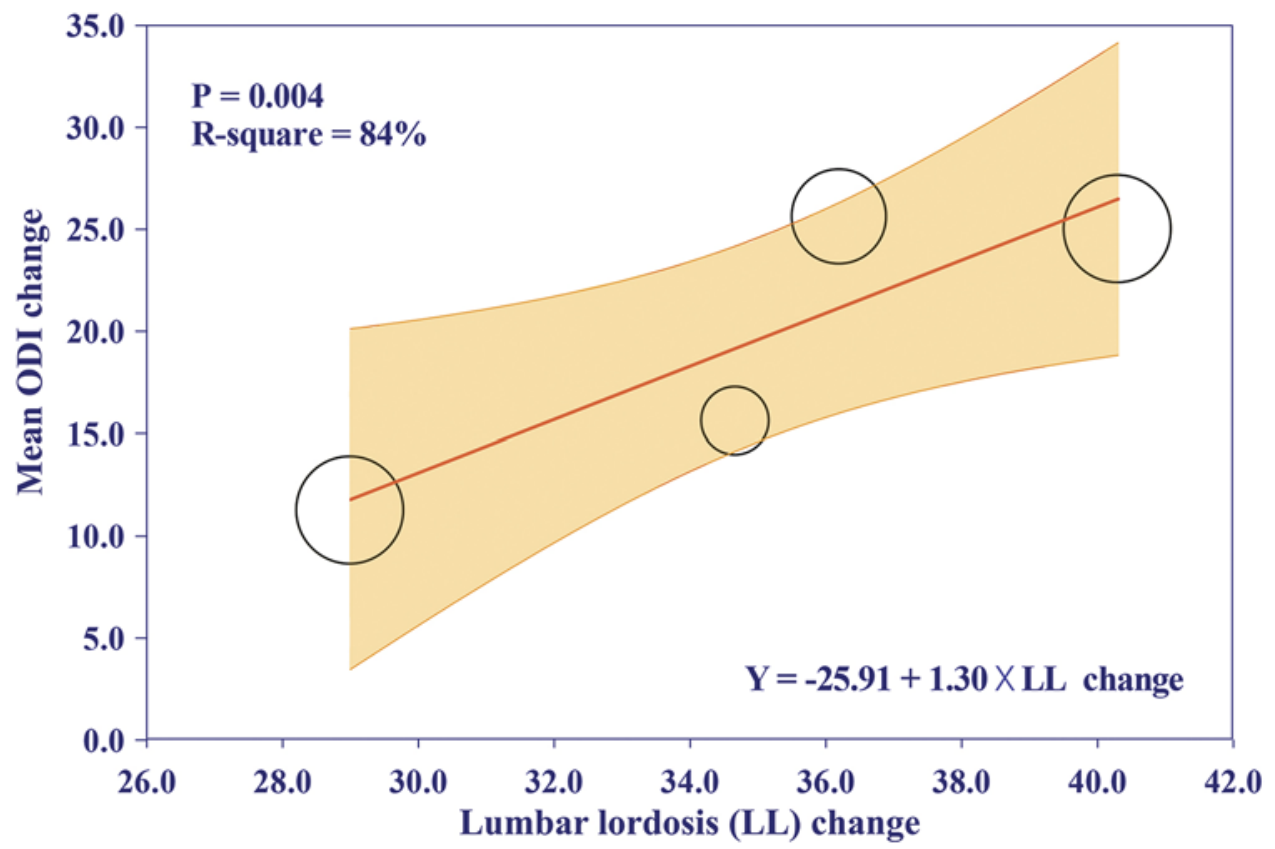

FIG. 7. Relationships between LL change after deformity correction and ODI improvement for patients with PDSI. Each circle is proportional to size of the study it represents. A positive treatment effect is indicated; an increase in LL change results in a reduction of the mean ODI. Figure is available in color online only.

ticular case. In our meta-analysis, we did not correct for the potential bias induced by surgeon preference or individual success rate; instead, we tried to evaluate the overall effectiveness of deformity-correction surgery in patients with PDSI in an effort to provide spine surgeons with an overall estimation of what can be expected in terms of risk and surgical outcomes. The third limitation is related to the rate of complications, which is a key outcome that reflects the effectiveness of surgery; many patients are reluctant to undergo deformity correction because of the risks of complications associated with the procedure. Because only 5 studies included in our meta-analysis reported complication rates, a statistical analysis of such outcomes would likely have been biased. Last, the majority of studies included in our meta-analysis were conducted in Korea and involved predominantly female patients. Furthermore, PI values have been shown to be smaller in Asian populations than in white populations. Therefore, it is difficult to judge precisely whether recovery of spinopelvic parameters to within the reference range was achieved, because LL is based on PI. In this context, our analysis might seem to lack generalizability. However, the incidence of PDSI is frequent in Asian women, particularly in Korea and Japan..$^{21}$ Therefore, the unequal representation of geographic region and sex in our analysis was an inevitable consequence of the epidemiological features of PDSI. Furthermore, it should be noted that the baseline PI angles were $58.9^{\circ}-62.8^{\circ}$ in patients from the United States and $55.1^{\circ}-61.0^{\circ}$ for patients in Korea, which suggests that racial differences in PI likely had only a minimal effect on the spinopelvic parameters assessed in our study.

\section{Conclusions}

Deformity correction substantially relieves back pain for approximately 2 years in adult patients with PDSI. Sufficient surgical restoration of LL in adult patients with PDSI leads to substantial improvements in disability and reduced decompensation. Deformity correction represents a viable therapeutic option for PDSI, but further technical advancements are necessary to increase ODI and reduce complication rates.

\section{Acknowledgments}

This research was supported by grant no. $\mathrm{HC} 15 \mathrm{C} 1288$ from the Korea Health Technology R\&D Project through the Korea Health Industry Development Institute, funded by the Ministry of Health \& Welfare, Republic of Korea.

\section{References}

1. Acosta FL Jr, McClendon J Jr, O'Shaughnessy BA, Koller H, Neal CJ, Meier O, et al: Morbidity and mortality after spinal deformity surgery in patients 75 years and older: complications and predictive factors. J Neurosurg Spine 15:667-674, 2011

2. Berjano P, Langella F, Ismael MF, Damilano M, Scopetta S, Lamartina C: Successful correction of sagittal imbalance can be calculated on the basis of pelvic incidence and age. Eur Spine J 23 (Suppl 6):587-596, 2014

3. Bernhardt M, Bridwell KH: Segmental analysis of the sagittal plane alignment of the normal thoracic and lumbar spines and thoracolumbar junction. Spine (Phila Pa 1976) 14:717721,1989

4. Blondel B, Schwab F, Bess S, Ames C, Mummaneni PV, Hart $\mathrm{R}$, et al: Posterior global malalignment after osteotomy for sagittal plane deformity: it happens and here is why. Spine (Phila Pa 1976) 38:E394-E401, 2013

5. Booth KC, Bridwell KH, Lenke LG, Baldus CR, Blanke KM: Complications and predictive factors for the successful treatment of flatback deformity (fixed sagittal imbalance). Spine (Phila Pa 1976) 24:1712-1720, 1999 
6. Bridwell KH, Glassman S, Horton W, Shaffrey C, Schwab F, Zebala LP, et al: Does treatment (nonoperative and operative) improve the two-year quality of life in patients with adult symptomatic lumbar scoliosis: a prospective multicenter evidence-based medicine study. Spine (Phila Pa 1976) 34:2171-2178, 2009

7. Bridwell KH, Lenke LG, Lewis SJ: Treatment of spinal stenosis and fixed sagittal imbalance. Clin Orthop Relat Res (384):35-44, 2001

8. Bridwell KH, Lewis SJ, Lenke LG, Baldus C, Blanke K: Pedicle subtraction osteotomy for the treatment of fixed sagittal imbalance. J Bone Joint Surg Am 85-A:454-463, 2003

9. Burkett B, Ricart-Hoffiz PA, Schwab F, Ialenti M, Farcy JP, Lonner BS, et al: Comparative analysis of surgical approaches and osteotomies for the correction of sagittal plane spinal deformity in adults. Spine (Phila Pa 1976) 38:188-194, 2013

10. Cho KJ, Kim KT, Kim WJ, Lee SH, Jung JH, Kim YT, et al: Pedicle subtraction osteotomy in elderly patients with degenerative sagittal imbalance. Spine (Phila Pa 1976) 38:E1561E1566, 2013

11. Cho KJ, Suk SI, Park SR, Kim JH, Kang SB, Kim HS, et al: Risk factors of sagittal decompensation after long posterior instrumentation and fusion for degenerative lumbar scoliosis. Spine (Phila Pa 1976) 35:1595-1601, 2010

12. Cho KJ, Suk SI, Park SR, Kim JH, Kim SS, Lee TJ, et al: Short fusion versus long fusion for degenerative lumbar scoliosis. Eur Spine J 17:650-656, 2008

13. Cho SK, Shin JI, Kim YJ: Proximal junctional kyphosis following adult spinal deformity surgery. Eur Spine J 23:27262736, 2014

14. Fairbank JC, Couper J, Davies JB, O’Brien JP: The Oswestry low back pain disability questionnaire. Physiotherapy 66:271-273,1980

15. Gelb DE, Lenke LG, Bridwell KH, Blanke K, McEnery KW: An analysis of sagittal spinal alignment in 100 asymptomatic middle and older aged volunteers. Spine (Phila Pa 1976) 20:1351-1358, 1995

16. Good CR, Auerbach JD, O'Leary PT, Schuler TC: Adult spine deformity. Curr Rev Musculoskelet Med 4:159-167, 2011

17. Jaeschke R, Singer J, Guyatt GH: Measurement of health status. Ascertaining the minimal clinically important difference. Control Clin Trials 10:407-415, 1989

18. Jang JS, Lee SH, Kim JM, Min JH, Han KM, Maeng DH: Can patients with sagittally well-compensated lumbar degenerative kyphosis benefit from surgical treatment for intractable back pain? Neurosurgery 64:115-121, 2009

19. Jang JS, Lee SH, Min JH, Maeng DH: Influence of lumbar lordosis restoration on thoracic curve and sagittal position in lumbar degenerative kyphosis patients. Spine (Phila Pa 1976) 34:280-284, 2009

20. Kim HJ, Bridwell KH, Lenke LG, Park MS, Ahmad A, Song $\mathrm{KS}$, et al: Proximal junctional kyphosis results in inferior SRS pain subscores in adult deformity patients. Spine (Phila Pa 1976) 38:896-901, 2013

21. Kim KT, Chan CY, Lee SH, Huh DS, Son ES: Surgical correction in patients with lumbar degenerative kyphosis who had low bone mineral density: an analysis of 40 patients with a minimum follow-up of two years. Asian Spine J 9:65-74, 2015

22. Kim KT, Lee SH, Suk KS, Lee JH, Im YS, Seo EM: [Loss of sagittal balance and clinical outcomes following corrective osteotomy for lumbar degenerative kyphosis.] J Korean Orthop Assoc 44:83-92, 2009 (Korean)

23. Kim WJ, Kang JW, Kang SI, Sung HI, Park KY, Park JG, et al: Factors affecting clinical results after corrective osteotomy for lumbar degenerative kyphosis. Asian Spine J 4:7-14, 2010

24. Kim YJ, Bridwell KH, Lenke LG, Glattes CR, Rhim S, Cheh
G: Proximal junctional kyphosis in adult spinal deformity after segmental posterior spinal instrumentation and fusion: minimum five-year follow-up. Spine (Phila Pa 1976) 33:2179-2184, 2008

25. Kim YJ, Bridwell KH, Lenke LG, Rhim S, Cheh G: Sagittal thoracic decompensation following long adult lumbar spinal instrumentation and fusion to L5 or S1: causes, prevalence, and risk factor analysis. Spine (Phila Pa 1976) 31:2359_ 2366, 2006

26. Kuntz C IV, Shaffrey CI, Ondra SL, Durrani AA, Mummaneni PV, Levin LS, et al: Spinal deformity: a new classification derived from neutral upright spinal alignment measurements in asymptomatic juvenile, adolescent, adult, and geriatric individuals. Neurosurgery 63 (3 Suppl):25-39, 2008

27. Lafage V, Schwab F, Patel A, Hawkinson N, Farcy JP: Pelvic tilt and truncal inclination: two key radiographic parameters in the setting of adults with spinal deformity. Spine (Phila Pa 1976) 34:E599-E606, 2009

28. Lee CH, Chung CK, Jang JS, Kim SM, Chin DK, Ha Y: 'Lumbar degenerative kyphosis' is not byword for degenerative sagittal imbalance: time to replace a misconception. J Korean Neurosurg Soc 60:125-129, 2017

29. Lee CS, Lee CK, Kim YT, Hong YM, Yoo JH: Dynamic sagittal imbalance of the spine in degenerative flat back: significance of pelvic tilt in surgical treatment. Spine (Phila Pa 1976) 26:2029-2035, 2001

30. Lee CS, Lim YT, Kim E: [Clinical study of lumbar degenerative kyphosis.] J Korean Soc Spine Surg 4:27-35, 1997 (Korean)

31. Lee JC, So JW, Jo JH, Kim YI, Shin BJ: Comparative analysis of surgical options in the treatment of lumbar degenerative kyphosis. J Korean Soc Spine Surg 16:8-16, 2009

32. Lee JH, Kim KT, Lee SH, Kang KC, Oh HS, Kim YJ, et al: Overcorrection of lumbar lordosis for adult spinal deformity with sagittal imbalance: comparison of radiographic outcomes between overcorrection and undercorrection. Eur Spine J 25:2668-2675, 2016

33. Lee SH, Kim KT, Suk KS, Lee JH, Seo EM, Huh DS: Sagittal decompensation after corrective osteotomy for lumbar degenerative kyphosis: classification and risk factors. Spine (Phila Pa 1976) 36:E538-E544, 2011

34. Lee SS, Yoo JY, Rhim SC, Lee JW, Byun JH: [Dynamic changes of pelvis and lower extremities after operation in lumbar degenerative kyphosis.] J Korean Acad Rehabil Med 30:57-61, 2006 (Korean)

35. McCarthy I, O’Brien M, Ames C, Robinson C, Errico T, Polly DW Jr, et al: Incremental cost-effectiveness of adult spinal deformity surgery: observed quality-adjusted life years with surgery compared with predicted quality-adjusted life years without surgery. Neurosurg Focus 36(5):E3, 2014

36. Noshchenko A, Lindley EM, Burger EL, Cain CM, Patel VV: What is the clinical relevance of radiographic nonunion after single-level lumbar interbody arthrodesis in degenerative disc disease?: a meta-analysis of the YODA Project Database. Spine (Phila Pa 1976) 41:9-17, 2016

37. Rose PS, Bridwell KH, Lenke LG, Cronen GA, Mulconrey DS, Buchowski JM, et al: Role of pelvic incidence, thoracic kyphosis, and patient factors on sagittal plane correction following pedicle subtraction osteotomy. Spine (Phila Pa 1976) 34:785-791, 2009

38. Roussouly P, Gollogly S, Berthonnaud E, Dimnet J: Classification of the normal variation in the sagittal alignment of the human lumbar spine and pelvis in the standing position. Spine (Phila Pa 1976) 30:346-353, 2005

39. Scott J, Huskisson EC: Graphic representation of pain. Pain 2:175-184, 1976

40. Slobodyanyuk K, Poorman CE, Smith JS, Protopsaltis TS, Hostin R, Bess S, et al: Clinical improvement through non- 
operative treatment of adult spinal deformity: who is likely to benefit? Neurosurg Focus 36(5):E2, 2014

41. Smith JS, Shaffrey CI, Berven S, Glassman S, Hamill C, Horton W, et al: Improvement of back pain with operative and nonoperative treatment in adults with scoliosis. Neurosurgery 65:86-94, 2009

42. Soroceanu A, Diebo BG, Burton D, Smith JS, Deviren V, Shaffrey C, et al: Radiographical and implant-related complications in adult spinal deformity surgery: incidence, patient risk factors, and impact on health-related quality of life. Spine (Phila Pa 1976) 40:1414-1421, 2015

43. Sparrey CJ, Bailey JF, Safaee M, Clark AJ, Lafage V, Schwab F, et al: Etiology of lumbar lordosis and its pathophysiology: a review of the evolution of lumbar lordosis, and the mechanics and biology of lumbar degeneration. Neurosurg Focus 36(5):E1, 2014

44. Takemitsu Y, Harada Y, Iwahara T, Miyamoto M, Miyatake Y: Lumbar degenerative kyphosis. Clinical, radiological and epidemiological studies. Spine (Phila Pa 1976) 13:1317_ 1326, 1988

45. Taneichi H: Update on pathology and surgical treatment for adult spinal deformity. J Orthop Sci 21:116-123, 2016

46. Terran J, McHugh BJ, Fischer CR, Lonner B, Warren D, Glassman S, et al: Surgical treatment for adult spinal deformity: projected cost effectiveness at 5-year follow-up. Ochsner J 14:14-22, 2014

47. Terran J, Schwab F, Shaffrey CI, Smith JS, Devos P, Ames CP, et al: The SRS-Schwab Adult Spinal Deformity Classification: assessment and clinical correlations based on a prospective operative and nonoperative cohort. Neurosurgery 73:559-568, 2013
48. Vedantam R, Lenke LG, Keeney JA, Bridwell KH: Comparison of standing sagittal spinal alignment in asymptomatic adolescents and adults. Spine (Phila Pa 1976) 23:211-215, 1998

49. Xie J, Zhang Y, Wang Y: [Treatment of spinal stenosis associated with lumbar degenerative kyphosis through posterior approach.] Zhongguo Xiu Fu Chong Jian Wai Ke Za Zhi 23:1092-1096, 2009 (Chinese)

\section{Disclosures}

The authors report no conflict of interest concerning the materials or methods used in this study or the findings specified in this paper.

\section{Author Contributions}

Conception and design: SM Kim, Chin, JK Lee, Yoon, Hong, $\mathrm{Ha}$. Acquisition of data: $\mathrm{CH}$ Lee. Analysis and interpretation of data: $\mathrm{CH}$ Lee. Drafting the article: $\mathrm{CH}$ Lee. Critically revising the article: Chung, Hong, CH Kim. Reviewed submitted version of manuscript: Chung, Jang, SM Kim, Chin, JK Lee, Yoon, Hong, Ha, CH Kim, Hyun. Statistical analysis: CH Lee. Administrative/ technical/material support: Jang. Study supervision: Chung, SM Kim, Chin, Yoon, Ha, Hyun.

\section{Correspondence}

Chang-Hyun Lee, Department of Neurosurgery, Ilsan Paik Hospital, Inje University College of Medicine, 170, Juwharo, Ilsan Seo-gu, Goyang, Gyeonggi 10380, Republic of Korea. email: imspinesurgeon@gmail.com. 